\title{
DIREITO DOS ANIMAIS E O CONTROLE DA LEISHMANIOSE: NOVAS PERSPECTIVAS
}

\section{Mery Chalfun ${ }^{1}$ \\ Francesca Odetta Santos Ribeiro Cosenza ${ }^{2}$}

\section{RESUMO}

A presente pesquisa tem por objetivo destacar a doutrina do direito dos animais, e sob este ângulo, questionar eticamente a eutanásia como forma tradicional de controle da leishmaniose, além de salientar a existência de novas possibilidades, e necessidade de implementação. Observa-se que animais permanecem sendo retirados de seus lares e eutanasiados para controle de doenças, tendo como argumento a necessidade de meio ambiente sadio, notadamente entre famílias mais carentes e periferias. O reconhecimento da senciência, ética animal e como sujeito de direitos impõe reformulação do pensamento humano e uma nova diretriz no controle de zoonoses.

Palavras- Chave: Direito dos Animais; senciencia; leishmaniose; eutanásia; ética

\section{ANIMAL RIGHTS AND CONTROL OF LEISHMANIOSIS: NEW PERSPECTIVES}

\section{ABSTRACT}

The present research aims to highlight the doctrine of animal rights, and from this angle ethically questioning euthanasia as a traditional form of control of leishmaniasis, besides emphasizing the existence of new possibilities, and the need for implementation. It is observed that animals remain removed from their homes and euthanized to control diseases, having as an argument the need for a healthy environment, especially among poor families and peripheries. The recognition of sentience, animal ethics and as subject of rights imposes reformulation of human thought and a new guideline in the control of zoonoses.

Key words: Animal Rights; sentience; leishmaniasis; euthanasia; ethic

\section{INTRODUÇÃO}

O presente trabalho tem por fim a análise do controle de zoonoses através da eutanásia e proposta de novas formas de controle, notadamente da doença chamada leishmaniose e conflito com a tutela dos animais. Questiona-se a imposição da eutanásia como meio de solução e a falta de ética neste padrão, pois novas formas devem ser adotadas.

$\mathrm{Na}$ verdade, predomina um pensamento antropocêntrico, ainda que alargado, na qual a preocupação maior é o homem e o meio ambiente saudável, fundamental para sua vida.

\footnotetext{
${ }^{1}$ Doutoranda (PPGD-UVAIRJ). Mestre em Direito pela UNESA. Professora da Universidade Veiga de Almeida. Membro da CPDA (OAB\RJ) e do Instituto Abolicionista Animal. E-mail: merychalfun @ hotmail.com 2 Mestre em Engenharia de Produção pela Universidade Federal do Rio de Janeiro - UFRJ. Professora permanente e pesquisadora da Universidade Veiga de Almeida. E-mail: francesca.cosenza@ gmail.com
} 
Animais são protegidos contra crueldade em âmbito constitucional e infraconstitucional, no entanto, em regra, há uma visão de propriedade ou recurso natural que se insere no meio ambiente. Protege-se o animal de maus tratos, tendo como objetivo a proteção do ser humano, pois aquele que assim procede é potencialmente perigoso para a sociedade.

Tendo em vista a proteção humana e meio ambiente, com frequência o controle de doenças ocorre através da morte de diversos animais, o que pode ser observado em casos conhecidos como vaca louca, gripe aviária e na leishmaniose. Falta reflexão e respeito, pois são os atos humanos os principais responsáveis pelo desequilíbrio e surgimento de doenças.

Em diversos pontos de interesse ou conflito, é comum que o animal não humano seja sacrificado, ao invés de se tutelar sua vida e alternativas para solução dos problemas. No entanto, por outro lado, destaca-se a formação de um novo ramo do direito, ou seja, direito dos Animais, defendendo uma natureza jurídica na qual animais são tutelados como sujeitos de direitos. Em visão contemporânea não são protegidos como meros recursos naturais ou propriedade, mas como seres sensíveis que devem ter suas vidas, integridade física e psíquica respeitadas. No âmbito Civil e familiar, expressões como propriedade, dono, coisa são questionadas e substituídas por sujeitos, guardiões, tutores, adoção. A afetividade e as famílias multiespécies são uma realidade que se contrapõem ao controle de doenças através da morte forçada e imposta de animais não humanos.

Assim, animais serem retirados e "eutanasiados" para controle de doenças e suposto meio ambiente sadio é uma realidade cada vez mais questionada e inaceitável. Deve-se considerar o meio ambiente e os interesses humanos, mas também dos não humanos. $\mathrm{O}$ reconhecimento da senciência animal e consequentemente como ser individualmente considerado impõe um tratamento ético em todas as esferas de relação e entre as diversas espécies, sejam humanas e não humanas.

A problemática consiste na seguinte questão: Animais devem ser mortos como forma de controle de zoonoses ou novas formas de controle devem ser adotadas? A retirada dos animais de seus guardiões, que não possuem condição de arcar com os elevados custos do medicamento Mitelforan, e eutanásia devem ser aceitas no combate da leishmaniose e interesse humanos ou deve-se reconhecer a dignidade dos não humanos, direito a vida e a ética animal? 
O objetivo geral da pesquisa é analisar a eutanásia como forma tradicional de controle da leishmaniose e novas possibilidades. Reconhecer os animais como sujeitos de direitos e a necessidade de outras formas de controle.

Os objetivos específicos são: (i) apresentar o direito dos animais e a natureza jurídica defendida em sua doutrina (ii) indicar princípios a serem adotados nas relações entre humanos e não humanos (iii) apontar a eutanásia como uma forma ultrapassada de controle de zoonoses, notadamente da leishmaniose (iv) destacar novas formas de controle que se ajustam a padrões de ética animal.

A abordagem metodológica da pesquisa será a revisão literária integrada e interdisciplinar nas searas do Direito, e estudos de casos.

\section{DIREITO DOS ANIMAIS}

Em visão tradicional a natureza jurídica dos animais pode ser analisada sob dois aspectos, ou seja; (i) no direito ambiental como recurso natural, bem difuso importante para o equilíbrio do ecossistema, bem comum do povo tutelados pelo Estado e pela sociedade.

A Carta Magna dedica capítulo inteiro à proteção ao meio ambiente, considerando em seu artigo 225 o meio ambiente ecologicamente equilibrado um direito fundamental, e, em seu parágrafo $1^{\circ}$, inciso $\mathrm{VII}^{3}$, proteção aos animais, dando-lhes natureza difusa e coletiva; portanto, bem sócio-ambiental de toda a humanidade, com imperativo moral e cláusula pétrea que demonstra preocupação ética de vedar práticas cruéis contra os animais. Assim, a proteção conferida aos animais torna-se dever do homem e verdadeiro exercício de cidadania.

No âmbito do Direito Civil (ii) Caio Mario da Silva Pereira definia "são objeto dos direitos os bens jurídicos" (2016, p. 336). Nesta perspectiva, animais são coisas, propriedade que se destina ao benefício humano, conforme se observa em diversos artigos do Código Civil e práticas tuteladas nesta seara, ou seja, é possível a compra e venda de animais, ações em decorrência de vícios ocultos e redibitórios, eutanásia a pedido do "dono".

Assim, por exemplo, os artigos 936, 1397, 1444, 1445 e 1447 do Código Civil definem os animais como propriedade, são objetos de penhor, alienação, usufruto, compra e

\footnotetext{
${ }^{3} \mathrm{CRFB} / 88$. "Art. 225: Todos têm direito ao meio ambiente ecologicamente equilibrado, bem de uso comum do povo e essencial à sadia qualidade de vida, impondo-se ao Poder Público e à coletividade o dever de defendê-lo e preservá-lo para as presentes e futuras gerações.

Parágrafo $1^{\circ}$ Para assegurar a efetividade desse direito, incumbe ao Poder Público:

Inciso VII: proteger a fauna e a flora, vedadas, na forma da lei, as práticas que coloquem em risco sua função ecológica, provoquem a extinção de espécies ou submetam os animais à crueldade."
} 
venda, utilizados em entretenimento como coisas, além de citar o homem como dono do animal, já que a responsabilidade por indenização em caso de eventual dano é do dono.

Há uma posição exageradamente conservadora quanto ao tratamento destinado aos animais, cada vez mais questionada e em transformação.

Atualmente doutrina e jurisprudência apontam para formação de uma nova forma de pensar, que ultrapassa de forma definitiva o antropocentrismo. Aponta-se para alteração da natureza jurídica dos animais, para sujeitos de direito. No âmbito familiar animais tornam-se membros de família multiespécies na qual o afeto é o princípio maior e o melhor interesse do animal considerado.

Expressões como propriedade, posse, dono são criticadas por darem a conotação de coisa, pretendendo-se a alteração desse status ${ }^{4}$. Projetos de lei preveem um novo tratamento jurídico em âmbito nacional e internacional.

Em março de 2017, Portugal aprovou a lei ${ }^{5}$ que institui o Estatuto Jurídico dos Animais, alterando o Código Civil e o Código de processo Civil português, reconhecendo a sua natureza de seres vivos dotados de sensibilidade. A exemplo do que aconteceu anteriormente no Código Civil Francês ${ }^{6}$. Há um reconhecimento da sensibilidade animal. Novos projetos e doutrina cada vez mais conferem novo tratamento para os animais. ${ }^{7}$

Caminha-se para o reconhecimento de uma doutrina que confere aos animais a natureza de sujeitos, com reconhecimento de dignidade e senciência. Com início na filosofia, aos poucos ganha espaço na esfera jurídica e na sociedade em um movimento internacional e nacional.

\footnotetext{
${ }^{4}$ Projetos de lei $n^{0} 3676$ de 2012; 6799 de $2013 ; 7991$ de 2014; 351 de 2015.

${ }^{5}$ Portugal, Lei n. ${ }^{\circ} 8 / 2017$.

${ }^{6} \mathrm{O}$ Código Civil Francês foi alterado pelo parlamento francês incluindo e reconhecendo os animais como seres sencientes. Reconhece desta forma que animais possuem sentimentos. Altera seu status jurídico de propriedade (artigo 528) para seres sencientes (novo artigo 514 e 515), sujeitos a serem considerados por si próprios e não por seu valor patrimonial.

Art. 515-14. du Code civil - Les animaux sont des êtres vivants doués de sensibilité. Sous réserve des lois qui les protègent, les animaux sont soumis au régime des biens". Alteração em 0112015.

7 "Nova lei considera animais domésticos como crianças ao invés de propriedades nos EUA. Nos últimos dias de dezembro, o estado norte -americano Illinois aprovou uma nova lei que considera animais como crianças em casos de custódia. A lei, que entrou em vigor em $1^{\circ}$ de Janeiro deste ano é semelhante a uma legislação do Alasca e deixa de considerar animais como propriedades para tratá-los como seres vivos que merecem ter seus melhores interesses atendidos.

Disponível em <https://www.anda.jor.br/2018/02/nova-lei-considera-animais-domesticos-como-criancas-aoinves-de-propriedades-nos-eua/> Acesso em 08.02.2018
} 
Assim, observa-se que ao longo da história animais foram explorados e desrespeitados, em teorias como de Descartes que comparou o animal a uma coisa, uma máquina. Não obstante, em paralelo, muitos filósofos, cientistas e estudiosos se dedicaram a compreender o bem-estar dos animais, questionar sua natureza jurídica e buscar uma tutela mais efetiva. A sociedade se sensibiliza e busca novas formas de convivência não baseadas na exploração, mas sim no respeito e solidariedade.

Por volta de 1970 o movimento em prol do reconhecimento do direito dos animais em esfera nacional e internacional ganhou espaço, o termo especismo, ou seja, a desconsideração por espécies que não sejam a humana. Livros foram e são lançados com teorias que incluem o animal na esfera de consideração moral, como por exemplo o livro Libertação Animal do filósofo Peter Singer, com o princípio da igual consideração de interesses e Jaulas Vazias do filósofo Tom Regan, incluindo os animais como sujeitos de uma vida. A temática e reflexão sobre os animais ganha espaço. Forma-se uma disciplina autônoma, com reflexos ambientais e para o animal individualmente considerado, cursos de extensão, disciplinas autônomas, pósgraduação, mestrados e doutorados, congressos abordando a questão animal, as crueldades sofridas em suas tristes realidades cotidianas. ${ }^{8}$

Forma-se um novo ramo do direito com preceitos doutrinários nos quais animais possuem titularidade de direitos como vida, liberdade, integridade física e psíquica. Animais como sujeitos de direito, como entes despersonalizados ou como sui generis. Animais com direito a vida digna e um mínimo existencial. Respeito por sua natureza e essência, liberdade para viverem com seus pares em conformidade com suas necessidades inerentes, independente do homem ou para o proveito deste.

Se até então a proteção dos animais advinha principalmente do interesse do homem, seja em decorrência do direito de propriedade ou importância do meio ambiente, hoje, o reconhecimento de que animais são seres sencientes e com capacidades lhes confere proteção em decorrência de sua própria natureza.

Sob estes aspectos, torna-se insustentável admitir que o controle de zoonoses, exercido pelo Poder Público, ocorra simplesmente com a retirada dos animais de seus lares e mortos, não sendo acompanhada de políticas sociais preventivas e mais humanas.

\footnotetext{
${ }^{8}$ Exemplos: em 2016 foi inserida na grade de eletivas ou tópicos no curso de Direito da Universidade Veiga de Almeida no Rio de Janeiro. Em 2018 a Facha inicia a primeira pós-graduação em Direito dos Animais no Rio de Janeiro. A UFBA possui linha de pesquisa e disciplina sobre a questão animal no mestrado e doutorado.
} 


\section{PRINCÍPIOS ÉTICOS PARA OS ANIMAIS}

Com base no reconhecimento da senciência, sustentada de forma embrionária por Jeremy Benthan em 1974, princípios são adotados e devem ser aplicados aos animais na atualidade. Havia já naquela época um questionamento quanto ao tratamento conferido aos animais que se sustentava em sua capacidade de sofrer e com base neste a necessidade de inclusão na esfera de considerações morais. Ética e moral conduzindo as ações humanas quanto aos não humanos. Em sua célebre frase questionou: “O problema não consiste em saber se os animais podem raciocinar; tampouco interessa se falam ou não; o verdadeiro problema é este: PODEM ELES SOFRER?” (BENTHAM, 1974, p. 69)

Em 2012 a senciência animal foi devidamente reconhecida pela ciência pondo fim a qualquer controvérsia que porventura ainda pudesse existir. Assim, constatou-se que animais possuem vontade, medo, estresse, dor, felicidade através da Declaração de Cambridge (The Cambridge Declaration of Consciousness), datada de julho de 2012, firmada por cientistas de instituições como a Universidade de Stanford, o Massachusetts Instituteof Technology (MIT) e o Instituto Max Planck, redigido por Philip Low, em evento que contou com a presença de Stephen Hawking.

Tendo por base principalmente a senciência há um reconhecimento de que animais não humanos devem ter direitos inerentes e sua dignidade respeitada.

Destaque-se que quando se trata de dignidade da pessoa humana há um consenso de que não podem ser tratados como objetos, instrumentos ou coisas. A dignidade está relacionada a direitos como vida, liberdade, igualdade, integridade, respeito, sendo o direcionador de todos os direitos humanos. Inaceitável por exemplo que qualquer ser humano seja sacrificado ou morto contra sua vontade, em decorrência de uma doença. Tanto que a eutanásia, ainda quando desejada pelo ser humano, demanda diversos questionamentos.

A dignidade é o valor de todos os direitos fundamentais e ordenamento jurídico. $\mathrm{O}$ princípio da dignidade humana encontra amparo no art. $1^{\circ}$ inc. III da Constituição Federal de 1988, e no âmbito internacional na Declaração Universal dos Direitos do Homem. "Art. 1": Todas as pessoas nascem livres e iguais em dignidade e direitos. São dotadas de razão e consciência e devem agir em relação umas às outras com espírito de fraternidade.” Destacase, portanto, a pessoa humana como o centro de todas as preocupações e a base de todos os direitos. 
Entretanto, a dignidade humana também deve ser vislumbrada de forma a promover um comportamento ético, visando não apenas a uma perspectiva individual, mas também preocupação com as demais criaturas, com outras formas de vida.

Dignidade: (...) a qualidade intrínseca e distintiva reconhecida em cada ser humano
que o faz merecedor do mesmo respeito e consideração por parte do Estado e da
comunidade, implicando, neste sentido, um complexo de direitos e deveres
fundamentais que assegurem a pessoa tanto contra todo e qualquer ato de cunho
degradante e desumano, como venham a lhe garantir as condições existenciais
mínimas para uma vida saudável, além de propiciar e promover sua participação
ativa e co-responsável nos destinos da própria existência e da vida em comunhão
com os demais seres humanos.( SARLET, 2004, p. 62)

Afirmar que a dignidade é inerente apenas ao ser humano, em decorrência de sua racionalidade, autodeterminação, liberdade, autonomia, é demonstrar uma concepção extremamente antropocêntrica. Além disso, a dignidade de cada indivíduo deve se refletir não apenas em si próprio, mas também a todo grupo social, e, por que não dizer, a todos os seres vivos, implicando em um permanente olhar para o outro, seja ele animal humano ou não humano. Necessária a extensão do princípio da dignidade para os animais não humanos.

Conforme Fábio de Oliveira, os animais devem ser incluídos na consciência do mínimo existencial, englobando as condições físicas, valores psíquicos, e, apesar de normalmente apenas o homem estar sendo atingido por estes preceitos, a dignidade, que está sempre acompanhada do mínimo existencial, deve englobar os animais.

Diante das diversas semelhanças existentes, pela condição de ser vivo, e do respeito que se devem nutrir pelas demais espécies e pela própria natureza, a harmonia e a dignidade de todo ser sensível devem ser preservadas.

Como assevera o filósofo francês Michel Serres (1991), é hora de se romper com o contrato social e pactuar um novo contrato, no qual a natureza e todas as suas espécies devem ser respeitadas, um contrato natural, de harmonia e respeito entre todas as espécies, com fim da exploração, do desrespeito, do entendimento de que a espécie humana é superior, até porque a natureza, apesar de paciente, tem demonstrado que o homem nada mais é que uma pequena parte de todo Universo.

Ressalte-se em outra área do saber os princípios abordados na bioética e biodireito, pois fundamentais na limitação do avanço científico e questões médicas, sanitárias. Apesar da bioética nascer voltada para questões exclusivamente humanas e em seu benefício é possível vislumbrar sua extensão para os animais não humanos dentro de uma perspectiva de titularidade de direitos fundamentais. 
Direitos e princípios como vida, solidariedade, responsabilidade, dignidade que dão origem e se destacam na chamada trindade ou tríade bioética, ou seja, autonomia, beneficêncialnão maleficência e justiça e limitam o avanço e controle de doenças de forma ética em relação aos seres humanos.

Questiona-se a aplicação de novas técnicas e o controle de doenças, é preciso resguardar a dignidade da pessoa humana, mas também utilizar esses princípios quando se trate de vidas não humanas, questionar sobre a dignidade dos animais, se novas técnicas podem ser adotadas, o progresso científico não deve ser alcançado à custa de vidas inocentes, simplesmente por pertencerem a outras espécies. O controle de doenças não deve se dar da forma mais fácil, barata e desconsiderando o interesse maior de todo ser de permanecer vivo.

É hora de ultrapassar o paradigma antropocêntrico, como Albert Schweitzer bem afirmou "O erro da ética até o momento tem sido a crença de que só deve aplicar-se em relação aos homens".

Quanto à autonomia (tríade bioética) se manifesta através do consentimento livre do indivíduo, e neste caso devem ser considerados de forma especial os seres mais vulneráveis, como crianças e também animais.

Animais possuem vontades, cada um deve ser considerado individualmente como um sujeito consciente e com vontade.

\footnotetext{
Se olharmos a questão "com olhos imparciais", veremos um mundo transbordante de animais que são não apenas nossos parentes biológicos, como também nossos semelhantes psicológicos. Como nós, esses animais estão no mundo, conscientes do mundo e conscientes do que acontece com eles. E, como ocorre conosco, o que acontece com esses animais é importante para eles, quer alguém mais se preocupe com isto ou não. A despeito de nossas muitas diferenças, os seres humanos e os outros mamíferos são idênticos neste aspecto fundamental, crucial, nós e eles somos sujeitos de uma vida. (REGAN, 2006, p.72)
}

Animais demonstram com seus comportamentos e linguagem própria, suas escolhas, basta observar: A felicidade de um cão quando seu guardião chega em seu lar ou sua tristeza quando é deixado; o desespero da mãe quando o filhote é retirado; a busca pelo abrigo, comida e água de animais abandonados, a tristeza de um animal aprisionado, o desespero e tristeza quando sente a proximidade da morte. Todos se pudessem falar a linguagem dos humanos gritariam bem alto suas opções pela vida de forma digna, com liberdade e respeito.

Quanto à beneficência e não maleficência (tríade bioética) deve ser considerado o maior bem do paciente, ou seja, bonun facere, ou de outro lado não fazer o mal. Devem ser promovidas ações positivas e danos previsíveis evitados. Pergunta-se qual o bem gerado 
quando um animal é retirado de seu tutor e morto, ao invés de ser tratado? É comum que cães com leishmaniose sejam retirados das famílias carentes e mortos. A "eutanásia” ainda é utilizada como forma de controle da doença quando seu guardião não possui condições de arcar com os custos do medicamento para uso não humano. No entanto, a eutanásia, na verdade boa morte, deveria ter como objetivo abreviar o sofrimento, o que não se observa neste caso, no qual toda família sofre, animal humano tutor e não humano com a doença.

Devem ser utilizados os avanços científicos e promover o bem, através de políticas públicas de prevenção e da permissão de uso de outros medicamentos, considerados seguros e eficientes, voltados a tratamentos que não gerem sofrimento e desconsideração pela vida humana e não humana.

A justiça (tríade bioética) deve ser aplicada através da distribuição de benefícios, novas técnicas e medicamentos. Igual consideração de interesses para todos, incluindo as demais espécies. Deve haver uma igualdade moral, em que os interesses de todos os interessados, incluindo animal humano e não humano, sejam considerados.

Por fim, em uma perspectiva de direito de família, não se pode deixar de citar e destacar os princípios da afetividade e melhor interesse, pois no âmbito familiar observa-se a extensão destes para os animais não humanos, membros da nova família multiespécies. A família na atualidade tem como máximas; o amor e o afeto em variadas formas, inclusive entre humanos e não humanos, amor e respeito entre homem e cachorro ou gato. O convívio afetivo se destaca e a afetividade entre humanos e não humanos no âmbito familiar é crescente, reforçando uma natureza jurídica de sujeitos nas quais as preocupações com veterinário, alimentação, passeios, saúde física e mental, guarda responsável e afetos são uma constante.

As famílias observam o que é melhor para o animal, este é considerado, seus interesses são observados, sendo comum que as famílias optem por viagens nas quais animais são bemvindos, restaurantes, organizem suas vidas tendo o animal um centro de interesses. Gestos de amor, afeto durante e após a morte, já que sepultamentos, cremações, homenagens são realizadas de forma organizada como um verdadeiro membro da família.

Assim como permitir a retirada compulsória de um ente amado e considerado para uma morte imposta e sem qualquer consideração? Como não observar a dignidade, autonomia, beneficência, não maleficência, justiça, amor e melhor interesse dos animais não humanos? São questões a serem consideradas no tratamento da leishmaniose. Esta imposição 
traz sofrimento para humanos e não humanos. Eticamente inaceitável e contrário aos pensamentos mais contemporâneos de convívio, respeito e tutela de humanos e não humanos.

\section{ZOONOSES - LEISHMANIOSE E EUTANÁSIA}

A leishmaniose é uma doença infecciosa, causada por protozoários do gênero Leishmania e da família Trypanosomatidae. De modo geral, essas enfermidades se dividem em leishmaniose tegumentar (ou cutânea), que ataca a pele e as mucosas, provocando feridas e leishmaniose visceral (ou calazar), que ataca órgãos internos de forma sistêmica, principalmente o fígado, o baço e a medula óssea.

A leishmaniose é provocada pelo protozoário denominado Leishmania e é transmitida pela picada de insetos vetores, os flebotomíneos, conhecidos popularmente como "mosquito palha", "cangalhinha", entre outros nomes, que variam de acordo com a região geográfica em que se encontrem.

O contágio não se dá pelo contato direto com o infectado, ele ocorre quando uma fêmea de flebotomíneo infectada se alimenta do sangue de um mamífero sadio, transmitindo o protozoário para ele.

Muito embora, não haja transmissão direta, desde 1908, quando houve os primeiros relatos da presença dos parasitas em canídeos na Tunísia, os cães domésticos, têm sido considerados como os principais reservatórios da Leishmaniose Visceral nos centros urbanos (SILVA 2005, p. 324), sendo, portanto, uma zoonose.

Apesar de ser uma enfermidade tratável, a Leishmaniose não tem cura e pode levar à morte. O tratamento humano é disponibilizado pelo Sistema Único de Saúde (SUS), que fornece gratuitamente os medicamentos. Contudo, o medicamento não é capaz de eliminar completamente o parasita e a medicação é disponibilizada apenas para uso humano, sendo expressamente vedado o seu uso em animais não humanos.

Em razão da gravidade da doença, que ataca órgãos internos de forma sistêmica, principalmente o fígado, o baço e a medula óssea e pode levar o ser humano a óbito em $90 \%$ (noventa por cento dos casos), o Ministério da Saúde, amparado pela Portaria Interministerial $\mathrm{n}^{\circ} 1.426$ de 11 de julho de 2008, proibiu a distribuição do medicamento de uso humano para tratar da Leishmaniose Visceral em cães, determinando, para estes casos, sua eliminação, seguindo a orientação da alínea "c" do art. $3^{\circ}$ do Decreto 51.838, de 14 de março de 1963. 
A problemática envolvendo a proibição da distribuição de medicamentos humanos (Glucantime e Anfotericina Lipossomal) para uso em cães infectados pela Leishmaniose pelo Ministério da Saúde é fundamentada pela probabilidade do parasita desenvolver resistência, induzindo à seleção de cepas resistentes aos medicamentos utilizados para tratamento em seres humanos; pelo fato de não haver evidências científicas de redução ou interrupção da transmissão, nesse caso, o animal permanece como reservatório de infecção para o vetor; e pelo risco do proprietário abandonar o protocolo prescrito pelo médico veterinário, assim que o animal deixe de apresentar os sintomas, exibindo boa aparência, o que geralmente ocorre com o decorrer do tratamento.

No dia 01 de setembro de 2016, o Ministério da Agricultura Pecuária e Abastecimento e o Ministério da Saúde assinaram a Nota Técnica Conjunta $n^{\circ}$ 001/2016 - MAPA/MS, permitindo a emissão, pelo Ministério da Agricultura Pecuária e Abastecimento, do registro do medicamento Mitelforan $2 \%$ solução oral para tratamento de cães portadores de Leishmaniose Visceral, permitindo assim o tratamento de cães portadores da Leishmania, sem ofender a Portaria Interministerial $\mathrm{n}^{\mathrm{o}} 1.426 / 2008$, pois não se trata de medicamento de uso humano.

Mesmo com a possibilidade de tratamento, o cão doméstico continua a ser considerado como um dos principais reservatórios do parasita em área urbana (embora outros mamíferos também possam estar envolvidos na transmissão) e, como não há cura, mesmo não apresentando mais os sinais clínicos, continuam sendo considerados como reservatórios e, consequentemente, um fator de risco para saúde pública. Por esta razão, o Ministério da Saúde continua a recomendar a eutanásia como uma das formas de controle da Leishmaniose Visceral, para os cães não tratados.

Contudo, o uso da eutanásia já se mostrou, além de cruel, ineficiente como método de controle da Leishmaniose Visceral.

\section{INEFICÁCIA DA EUTANÁSIA COMO MÉTODO DE CONTROLE DA LEISHMANIOSE VISCERAL.}

Durante muitos anos o Brasil segue a eutanásia como protocolo para controle as Leishmaniose Visceral. Muito já se debateu e pouco se estudou sobre a eficácia deste tipo de procedimento. 
Em seu artigo intitulado "Delittuosi delitti" Carlos Henrique Nery Costa, Doutor em Saúde Pública Tropical pela Universidade de Harvard, realizou um trabalho de pesquisa sobre os efeitos da eliminação de reservatórios do parasita como método para controle da Leishmaniose Visceral.

Através da revisão da literatura e da descrição histórica, Costa analisou protocolos adotados na Índia, na China, na antiga União Soviética e no Brasil para o combate à Leishmaniose Visceral avaliando o papel do cão e sua eliminação como medida de controle.

Em seu estudo, verificou que o controle da Leishmaniose nesses locais se deu pela combinação de métodos tradicionais, como a identificação e tratamento de casos humanos, a eliminação de cães e o uso de DDT para o tratamento da habitação. Contudo, ressalta que o "sucesso principal foi alcançado somente após o uso de DDT para o tratamento da habitação", principalmente na China, onde se tem uma variação antropótica (só acomete humanos) da doença. Contudo, assevera que nos locais onde há alta pressão de transmissão, como na área noroeste da China e na cidade de Kyzylorda (antiga União Soviética - atualmente pertencente ao Cazaquistão), e que apresentam a variação zoonótica da doença, o protocolo adotado não apresentou resposta tão eficiente às ações de controle. O que demonstra a dificuldade em se controlar a transmissão da Leishmaniose Visceral, mesmo aplicando a eliminação em massa de cães, infectados ou não.

Quanto ao procedimento em território brasileiro, Costa aponta que, no estado do Ceará, onde deu-se início ao protocolo de controle, em 1953, constatou-se a redução de quase 60\% (sessenta por cento) de incidência na contaminação de pessoas em 14 municípios, onde houve a aplicação do DDT, e um aumento de quase 12\% (doze por cento) em 14 municípios onde apenas foi praticada a eutanásia de cães. Já, na região do Vale do Rio Doce, foi aplicado o protocolo clássico (tratamento das pessoas infectadas, eliminação dos cães soropositivos para Leishmania Chagasi e uso do DDT), a incidência da doença caiu para zero.

Costa afirma que, apesar do estudo apontar que o uso de DDT tenha apresentado um certo efeito protetor contra a intensidade da transmissão da leishmaniose, nunca houve um estudo controlado que indicasse a sua eficácia.

Outro apontamento feito por Costa, e que merece ser ressaltado, é, que no Brasil, o cão doméstico não é o único mamífero apontado como reservatório do parasita. Vivemos em cidades infestadas de roedores, marsupiais, primatas, etc., que também são potenciais reservatórios do parasita, o que demonstra que a eliminação dos reservatórios é muito menos 
eficaz do que uma política pública voltada à vacinação, tratamento dos infectados (homens e animais domésticos) e o uso de vacina, telas, inseticidas e repelentes.

Importante salientar que não há como eliminar a presença de cães nas áreas endêmicas, pois existe uma tendência cultural de se substituir os animais eutanasiados por animais mais jovens e mais sensíveis à infecção (SILVA, 2005), iniciando um novo ciclo da doença.

Este fato também foi apontado em artigo questionando a eficácia da eutanásia em cães com Leishmaniose Visceral, publicado pelos pesquisadores Carlos Saldanha, do Instituto de Comunicação e Informação Científica e Tecnológica em Saúde (Icict/Fiocruz), Érica Gaspar Silva, da Universidade do Estado do Rio de Janeiro (Uerj), e Rodrigo Vilani, da Universidade Federal do Estado do Rio de Janeiro (Unirio) (MACHADO, 2016).

Outro artigo realizado por pesquisadores da Fundação Oswaldo Cruz e do Centro de Ciências da Saúde, Universidade Federal do Rio de Janeiro, na região de Barra de Guaratiba, área considerada endêmica para Leishmaniose Visceral, no período de 2001 e 2002, com objetivo de pesquisar o papel do cão doméstico como reservatório principal da Leishmaniose Visceral demonstra que, apesar das políticas clássicas de controle, com a eliminação de cães soropositivos, o número de humanos e canídeos infectados não apresentava queda significante (SILVA, 2005).

Os pesquisadores observaram que há uma maior incidência de cães infectados nas áreas próximas às matas, o que pode estar associado ao grande número de marsupiais infectados e ao grande número de vetores presentes no local, resultando em um elo entre os ciclos domésticos e silvestres da doença (SILVA, 2005), constatando a dificuldade de se combater a expansão da doença em áreas de alta pressão de transmissão.

A maioria dos estudos realizados demonstram que, mesmo com a eliminação de centenas de cães por ano, a incidência de Leishmaniose Visceral Humana manteve-se elevada em vários municípios brasileiros, onde se pode observar um crescente número de casos notificados e a expansão da transmissão em áreas anteriormente não afetadas, demonstrando que as medidas de controle voltadas à eliminação de cães em áreas endêmicas não apresentam resultados satisfatórios, demonstrando a necessidade da criação de uma política de saúde pública voltada à campanhas e programas de orientação à posse responsável de cães, campanhas de vacinação, ao manejo ambiental para controle dos vetores e à educação em 
saúde seriam instrumentos preventivos de controle da Leishmaniose Visceral mais eficazes do que a eutanásia de cães infectados.

\section{NOVAS POSSIBILIDADES - CONTROLE ÉTICO}

Diversas possibilidades são viáveis de forma a controlar de forma respeitosa e ética as zoonoses que podem atingir os animais. A eutanásia não é uma solução. Vacinação, controle químico e tratamento são formas viáveis que podem e já estão sendo adotadas.

\subsection{VACINAÇÃO}

Estudos apontam a vacinação como método eficaz de controle e prevenção da Leishmaniose Visceral nos cães e o bloqueio da transmissão do parasita ao vetor, constituindo uma importante estratégia de controle (ARTACHO, 2015).

Atualmente, no mercado brasileiro, é comercializada apenas uma vacina que promete prevenir a Leishmaniose Visceral canina, aprovada pelos critérios da Instrução Normativa 31/2007 (Ministério da Saúde e MAPA) e com registro no Ministério da Agricultura Pecuária e Abastecimento (MAPA), a vacina Leish-Tec®, produzida pelos laboratórios Hertape Calier Saúde Animal, desde que seja respeitado o protocolo de vacinação, adotado em conjunto com as outras medidas de prevenção, como o uso de repelentes e aplicação de inseticidas e telas de proteção.

Existem ainda outras vacinas em estudo.

\subsection{CONTROLE QÚÍMICO}

O controle químico também pode ser considerado como uma das medidas mais eficazes na redução de doenças transmitidas por vetores, pois age diretamente na eliminação do flebótomo, agente transmissor da Leishmania.

O uso de inseticidas é indicado por vários pesquisadores como método eficiente no combate à transmissão da leishmaniose, obtendo resultados satisfatórios em programas brasileiros de controle a vetores, onde houve a redução e controle de casos de Leishmaniose, dentre outras doenças (ARTACHO, 2015)

O uso de repelentes em coleira também é apontado como uma excelente ferramenta de prevenção, principalmente aliado ao tratamento dos cães doentes e às vacinas, em cães 
comprovadamente negativados para a Leishmaniose. No mercado encontramos duas marcas líderes, a Scalibor e a Seresto.

\subsection{TRATAMENTO}

Durante muitos anos o tratamento de cães portadores de Leishmania foi proibido no Brasil, utilizando-se a eutanásia como protocolo de controle da doença, conforme previsto na alínea "c" do Art. 3, do Decreto 51.838, de 14 de março de 1963. Em 2008, o Ministério da Saúde em conjunto com o Ministério da Agricultura, Pecuária e Abastecimento, por meio da Portaria Interministerial $\mathrm{n}^{\mathrm{o}} 1.426$ de 11 de julho de 2008, proibiu a distribuição de medicamento de uso humano ou não registrado em órgão competente, para o tratamento da Leishmaniose Visceral em cães, mantendo a eliminação dos cães infectados como protocolo de controle e punindo veterinários e tutores, em caso de descumprimento da citada norma $\left(\right.$ Art. $\left.5^{\circ}\right)$.

Munida de vários estudos, que versam sobre a ineficácia da eutanásia como forma de controle da Leishmaniose Visceral, a ONG de defesa animal Abrigo dos Bichos, considerando que a Portaria Interministerial $\mathrm{n}^{\mathrm{o}} 1.426 / 2008$, ao vedar a utilização de produtos de uso humano ou não registrados no competente órgão federal viola os referidos preceitos legais e, por consequência, indiretamente, a liberdade de exercício da profissão de veterinário prevista no inciso XIII do artigo $5^{\circ}$, da Constituição Federal, visto que poderia sofrer sansões, até mesmo ter seu registro cassado pelo Conselho, decidiu acionar a Justiça Federal, em São Paulo, contra a proibição da utilização de medicamentos de uso humano ou não registrados no Ministério da Agricultura, Pecuária e Abastecimento para tratamento da Leishmaniose Visceral Canina pela Portaria Interministerial no 1426/2008, obtendo a decisão favorável em primeira instância no TRF da $3^{\text {a }}$ Região, em junho de 2010, suspendendo a eficácia da Portaria Interministerial $n^{\circ} 1426 / 2008$, permitindo o tratamento de cães infectados com os medicamentos disponíveis no mercado (FREITAS, 2015).

Em janeiro de 2013, a $6^{\text {a }}$ Turma do Tribunal Regional Federal da $3^{\text {a }}$ Região STF, em sede de agravo de instrumento (AI $\mathrm{n}^{\circ}$ 0013792-50.2010.4.03.0000/MS), reconheceu a inconstitucionalidade da Portaria Interministerial n. 1.426, de 11 de julho de 2008, expedida pelo Ministério da Agricultura, Pecuária e Abastecimento e Ministério da Saúde que proibia o tratamento de cães infectados por Leishmaniose Visceral mantendo a suspensão de seus efeitos, quanto à prática da eutanásia canina. 
Em 2013, o Supremo Tribunal Federal (STF), manteve a decisão do Tribunal Regional Federal da $3^{\mathrm{a}}$ Região (TRF-3), mantendo a suspensão da eficácia da Portaria Interministerial $n^{\circ} 1426 / 2008$.

Com estas decisões, os órgãos públicos de Campo Grande (MS) ficaram impedidos de eutanasiar os animais como meio de controle da Leishmaniose Visceral Canina e de proibir o tratamento dos animais infectados.

No dia 01 de setembro de 2016, o Ministério da Agricultura Pecuária e Abastecimento e o Ministério da Saúde assinaram a Nota Técnica Conjunta $n^{\circ}$ 001/2016 - MAPA/MS, permitindo a emissão, pelo Ministério da Agricultura Pecuária e Abastecimento, do registro do medicamento Mitelforan $2 \%$ solução oral para tratamento de cães portadores de Leishmaniose Visceral, permitindo assim o tratamento de cães portadores da Leishmania, sem ofender a Portaria Interministerial $n^{\circ} 1.426 / 2008$, por não se tratar de medicamento de uso humano.

Em 2017 as Secretarias de Saúde de vários estados passaram a definir regras para o tratamento de cães, evitando a eutanásia, que somente poderá ser empregada caso as normas técnicas de segurança definidas não sejam atendidas.

Destaca-se por fim o Projeto de Lei $^{\circ} 2.388$, de 2015, apresentado pelo Sr. Josué Bengtson, que pretende disciplinar o controle da eutanásia de animais portadores de Leishmaniose Visceral Canina, conferindo ao tutor do cão, a escolha entre eutanasiar ou tratar seu animal de estimação (art. $2^{\circ}$ ), apresentando as regras que devem ser seguidas pelos tutores e pelos veterinários responsáveis pelo tratamento, caso opção seja o tratamento.

Um dos pontos positivos deste Projeto de Lei é a previsão do fornecimento de vacinas, financiadas pelo Poder Público, e oferecidas gratuitamente pelos Centros de Controle de Zoonoses e pelos canis municipais (art. $4^{\circ}$ e parágrafo único), mediante apresentação de exame comprobatório da não infecção do animal por Leishmaniose Visceral Canina, bancado e apresentado pelo tutor do animal, contudo, a eutanásia permanece como medida de controle, por opção do tutor.

\section{CONCLUSÃO}

A pesquisa demonstra que a eutanásia permanece sendo a forma mais usual de controle de zoonoses e que critérios, princípios da bioética, ética animal e direitos dos animais 
devem ser observados. No entanto, novos procedimentos e projetos de lei já consideram a substituição ou uma opção quanto à eutanásia nos casos de leishmaniose, resta tornar tais tratamentos mais acessíveis, principalmente para camada mais pobre da sociedade - as mais atingidas pela doença, além da conscientização quanto às formas preventivas, tratamento e novo olhar aos animais não humanos.

Critérios econômicos das famílias e no tratamento não devem ser impeditivos para se conferir dignidade e a possibilidade de cuidados com animais.

Sem sombra de dúvida, a permissão do uso de um medicamento largamente utilizado nos países europeus para tratamento de cães com Leishmaniose constituiu um grande avanço na luta pelo fim da eutanásia de animais como única forma de controle da doença. Contudo, o custo do Mitelforan é considerado alto, custando, em média, em torno de R\$710,00 (setecentos e dez reais) - frasco de 30ml a R \$ 1.809,00 (mil oitocentos e nove reais) - frasco de $90 \mathrm{ml}$, sendo que o animal pode precisar de mais de um frasco. Sendo proibitivo às famílias carentes e aos animais abandonados, que são muitos.

Porém, existem outros medicamentos utilizados para tratamento da Leishmaniose Visceral Canina, cujo custo é mais acessível, como é o caso da fórmula a base de Alopurinol desenvolvida pelo Doutor graduado em Doenças Tropicais e Saúde Internacional pelo Instituto de Medicina Tropical da Universidade de São Paulo (IMTUSP) André Luiz Soares da Fonseca que, no início de 2017, assumiu o Centro de Controle de Zoonoses de Campo Grande - MS, aplicando protocolos mais dignos e humanos no controle da doença em animais.

Segundo o Médico Veterinário e Diretor Clínico em Clínica Veterinária, Otávio Antônio Volpato, ouvido em conversa informal, o tratamento, aliado à aplicação de repelentes, pulverização de inseticidas dentro e fora das residências e canis, limpeza de terreno e quintal, destinação do lixo de forma correta, uso telas, entre outros meios de eliminação de vetores, reduz bastante a capacidade infectiva dos cães tratados, mas o animal continua a ser considerado como reservatório da doença. Por essa razão, o tratamento precisará de acompanhamento veterinário pelo resto da vida do animal.

Contudo, deve-se atentar que a permissão de tratamento de cães infectados com o medicamento Mitelforan, foi concedida por uma Nota Técnica Conjunta, assinada pelos Ministérios da Agricultura Pecuária e Abastecimento e da Saúde, que pode ser cancelada a qualquer momento, pois não traz a mesma segurança de uma norma legal. O mesmo pode 
acontecer com o tratamento realizado com autorização judicial, como é o caso da decisão do TRF - $3^{a}$ Região, que considerou inconstitucional a proibição ao tratamento, cujo entendimento poderá ser modificado a qualquer momento.

Por essa razão, deve se dar destaque ao Projeto de Lei ${ }^{\circ} 2.388$, de 2015, pois confere ao tutor do cão, a escolha entre eutanasiar ou tratar seu animal de estimação. Não obstante, sob a ótica do direito dos animais a eutanásia não deve ser uma opção, caso haja tratamento que proporcione uma vida digna ao animal.

Por outro lado, devemos atentar que o vetor da doença é o flebótomo, e que, atualmente as ações de combate ao mosquito tem se mostrado ineficazes, pois o Ministério da Saúde só autoriza a pulverização do veneno para combater os mosquitos quando há relato de casos de humanos infectados.

As pesquisas analisadas apontam que o melhor caminho para combater a Leishmaniose é com informação, educação e prevenção e para o efetivo controle da doença e uma efetiva ação pública sanitária voltada ao combate ao vetor, através da aplicação de inseticidas em locais endêmicos, campanhas de vacinação de cães, como ocorre com a vacinação contra a raiva, outra zoonose capaz de levar o ser humano a óbito, e a isenção ou redução de impostos nos preços finais dos medicamentos utilizados para prevenção e tratamento da Leishmaniose Visceral em cães, nas coleiras e repelentes desenvolvidos com a finalidade de evitar o contato de animais com o vetor transmissor da doença e sobre a vacina disponível no mercado.

Lembrando que a eutanásia é uma prática utilizada para interromper o sofrimento de um animal portador de moléstia incurável de maneira controlada e assistida por um profissional, não devendo ser usada como forma cruel de controle de uma zoonose cujo tratamento é considerado eficaz, se rigorosamente cumprido o protocolo, e que pode ser evitada com a adoção de políticas públicas sanitárias e com campanhas de vacinação, do contrário configura uma afronta aos princípios humanitários e grave ofensa ao inciso VII do parágrafo $1^{\circ}$ do art. 225 Constituição Federal.

\section{REFERÊNCIAS BIBLIOGRÁFICAS}

ARTACHO, Nathália Spina. A LEISHMANIOSE NO BRASIL E O CONFLITO IDEOLÓGICO: EUTANÁSIA OU TRATAMENTO?. Disponível no site: < 
http://bichosonline.vet.br/wp-content/uploads/2015/06/tratamento-leishmaniose.pdf> , acesso em 20/02/2018.

BENTHAM, Jeremy. Uma Introdução aos princípios da moral e da legislação. São Paulo: Abril Cultural, 1974. (Os Pensadores).

BOBBIO, Noberto. A Era dos Direitos. Tradução de Carlos Nelson Coutinho. Rio de Janeiro: Elsevier, 2004.

CHALFUN, Mery. Tutela dos direitos dos Animais: Travessia entre o bem-estarismo e o abolicionismo. Dissertação de Mestrado. Universidade Estácio de Sá - UNESA, 2009.

COSTA, Carlos Henrique Nery. Delittuosi delitti.<http://www.leishmania.it/?p=1469>

DINIZ, Maria Helena. O Estado Atual do Biodireito. São Paulo: Saraiva, 2014.

FREITAS, Danielli Xavier, TRF $3^{a}$ Região: Cada vez mais o judiciário cumpre seu institucional e ético papel no combate à eutanásia canina. Leishmaniose tem tratamento, não preconceito! - DIÁRIO ELETRÔNICO DA JUSTIÇA FEDERAL DA $3^{\text {a }}$ REGIÃO - Edição $\mathrm{n}^{\mathrm{o}} 105 / 2015$ - São Paulo, quinta-feira, 11 de junho de 2015 $<$ https://daniellixavierfreitas.jusbrasil.com.br/noticias/200076865/trf-3-regiao-cada-vez-maiso-judiciario-cumpre-seu-institucional-e-etico-papel-no-combate-a-eutanasiacanina?ref=topic_feed>, acesso em 20/02/2018.

PAIXÃO, Rita Leal. Experimentação animal: razões e emoções para uma ética. Tese de Doutorado. Fundação Oswaldo Cruz. Escola Nacional de Saúde Pública, 2001.

MACHADO, Carlos José Saldanha; SILVA, Erica Gaspar e VILANI, Rodrigo Machado. $O$ uso de um instrumento de política de saúde pública controverso: a eutanásia de cães contaminados por leishmaniose no Brasil. Saude soc. [online]. 2016, vol.25, n.1, pp.247-258. ISSN 0104-1290. http://dx.doi.org/10.1590/S0104-12902016146918.

PEREIRA, C. M. S. Instituições de direito civil. Vol. IV. Direitos Reais $24^{\mathrm{a}}$ ed. Rio de Janeiro: Forense, 2016.

PEREIRA, T. S. O princípio do "melhor interesse da criança" no âmbito das relações familiares. In: GROENINGA, G. e PEREIRA, R. (Coord.) Direito de Família e Psicanálise Rumo a uma nova epistemologia. Rio de Janeiro: Imago, 2003.

REGAN, Tom. Jaulas Vazias. Porto Alegre: Lugano, 2006.

ROMERO, Gustavo Adolfo Sierra. O Controle da Leishmaniose Visceral no Brasil: transformar é preciso. Cad. Saúde Pública vol.32 no.6 Rio de Janeiro 2016 http://dx.doi.org/10.1590/0102-311XCO010616. 
SARLET, Ingo Wolfgang. Dignidade da pessoa humana e direitos fundamentais na Constituição Federal de 1988. 3 ed. Porto Alegre: Livraria do Advogado, 2004.

SARLET, Ingo Wolfgang Sarlet; FENSTERSEIFER, Tiago. Algumas notas sobre a dimensão ecológica da dignidade da pessoa humana e sobre a dignidade da vida em geral. In: MOLINARO; MEDEIROS; SARLET; FENSTERSEIFER (Org.) A dignidade da vida e os direitos fundamentais para além dos humanos: uma discussão necessária. Belo Horizonte: Fórum, 2008.

SERRES, Michel. O Contrato Natural. Tradução: Beatriz Sidoux. Rio de Janeiro: Nova Fronteira, 1991.

SILVA, Alba Valéria Machado da Silva; PAULA, Adelzon Assis de; CABRERA, Maria Alice Airosa; CARREIRA, João Carlos Araújo. Leishmaniose em cães domésticos: aspectos epidemiológicos. Cad. Saúde Pública [online]. 2005, vol.21, n.1, pp.324-328. ISSN 16784464. http://dx.doi.org/10.1590/S0102-311X2005000100036.

SINGER, Peter. Libertação Animal. Porto Alegre: Lugano, 2004.

SOUZA, Ricardo Timm. Ética e animais - reflexões desde o imperativo da alteridade. <http://revistaseletronicas.pucrs.br/ojs/index.php/veritas/article/viewFile/2079/1573>

\section{SITES DE PESQUISA:}

Leishmaniose visceral. Disponível < http://portalms.saude.gov.br/saude-de-a-z/leishmaniosevisceral>, acesso em 16/03/2018.

http://diganaoaleishmaniose.blogspot.com.br/2011/07/seminario-promovido-pelodeputado.html https://www.apipa10.org/noticias/publicacoes-da-apipa/no-brasil/3153-stf-garante-otratamento-de-caes-com-leishmaniose-no-brasil.html http://web.trf3.jus.br/diario/Consulta/VisualizarDocumentosProcesso?numerosProcesso=2010 03000137926\&data=2015-06-11 